\title{
Moral Disengagement and Discrimination Experiences as Predictors of Bullying Among Korean-American Adolescents
}

\section{Authors:}

Jin Y. Shin, Ph.D. ${ }^{1}$

Shannon M. Davis, B. A. ${ }^{2}$

Thomas DiBlasi, M.A. ${ }^{3}$

\begin{abstract}
Affiliations:
1 Department of Psychology, Hofstra University, New York, U.S.A.

Email: jin.y.shin@hofstra.edu

2 Department of Mental Health Counseling, Hofstra University, New York, U.S.A.

Email: sdavis50@pride.hofstra.edu

3 Department of Psychology, Hofstra University, New York, U.S.A.

Email: thomas.a.diblasi@gmail.com
\end{abstract}

\section{Corresponding author:}

Jin Y. Shin, Ph.D.

Email: jin.y.shin@hofstra.edu

\begin{abstract}
This study aimed to examine the relationship between moral disengagement, and discrimination experiences, and bullying experiences among Korean-American adolescents. It was hypothesized that bullies would show higher levels of moral disengagement and discrimination when compared with non-bullies. It was also hypothesized that moral disengagement would be related to discrimination experiences. A secondary data analysis from a survey study of KoreanAmerican adolescents was conducted using a data set that consisted of survey responses on bullying and related experiences from 119 KoreanAmerican junior high school students. The results supported the hypothesis that bullies experienced higher levels of moral disengagement when compared to non-bullies, although bullies did not experience more discrimination than non-bullies. Moral disengagement was not related to discrimination experiences. This study found that gender played a role in moral disengagement. Boy bullies experienced higher levels of moral disengagement than any other comparison group. In general, boys experienced more discrimination than girls. Future studies need to explore these factors along with other social variables, such as family relationships and cultural value orientations, to delineate why certain KoreanAmerican adolescents become bullies and aggressors while others remain intact and resilient to adverse social and school experiences.
\end{abstract}

Keywords: bullying, moral disengagement, discrimination, Korean-American adolescents, adolescents 


\section{Introduction}

Bullying is a serious problem for adolescents all over the world. Nearly twothirds of adolescents experience some kind of bullying (1). Bullying is defined as "a negative action in which someone intentionally inflicts, or attempts to inflict, injury or discomfort upon another" (2). Often bullying is interpreted as a power struggle to determine the subordinate and the dominant individuals within a group, where the dominant member subjects the subordinate ones to pain and suffering, to exert and establish power over them and onlookers (3).

\section{Bullies \\ 1.1. Moral Disengagement among}

According Bandura, bullying is caused by a deficiency in moral agency $(4,5,6)$, which is the degree to which an individual can make moral decisions of right and wrong. While all individuals demonstrate variations in moral agency, those who deviate from societal norms in moral judgment are considered experiencing moral disengagement. Moral disengagement, or the ability to distinguish right from wrong, is most often selective in nature and can be easily turned on or off depending on the social situation (6). Bullies experience moral disengagement when they ignore what they have learned about morally acceptable behaviors. This keeps them from anticipating any adverse psychological consequences from hurting others, and cognitively shields them from recognizing social repercussions of their negative behaviors.

Bandura proposed that human beings model their behavior based on reactions and responses of others (6). Individuals recognize their behavior as right or wrong based on social responses of their peers. Behaviors that deviate from the social norms evoke a negative reaction from peers, which leads to the extinction of that behavior $(6,7)$. Bandura believed that divergence from these social norms occurs when an individual reconstructs their ideas of moral behavior, or their ideas of right and wrong (6).

Bullies reconstruct their moral behavior by dehumanizing the victim, justifying their behavior, or ignoring their behavior. This reconstruction of moral ideas about right and wrong can lead to prolonged moral disengagement. When bullies use dehumanization tactics, they often ascribe animalistic characteristics to their victims. This allows them to view the victim's life as holding less value than their own $(5,6,8)$. It is also understood that bullies tend to have a distorted moral reasoning that minimizes their sense of guilt and justifies their negative behavior $(6,9)$. Bullies may engage in cognitive moral disengagement to free themselves of guilt and remorse for bullying others $(6,10)$. They may rationalize their behaviors by convincing themselves that the person deserved to be bullied. Finally, bullies may intentionally ignore their own negative behaviors, or the fact that they have a bullying problem. The bullies may not hold themselves accountable for their actions, and deny their behaviors altogether. These three tactics (dehumanization, justification, ignoring) are helpful for the bullies to protect themselves from negative emotions and from thinking that they are inflicting harm on others (6).

Menesini, Palladino, \& Nocentini addressed a potential relationship between moral disengagement and bullying (11). They found that individuals turn off moral control to rationalize negative behavior, and that moral disengagement is positively correlated with being a bully. This is consistent with Bandura's theory, in which bullies cognitively protect themselves when hurting others $(6,11)$. Turner (12) found results similar to those of Menesini et al., (11), and also evaluated a possible 
correlation between bullying and effective pro-social behaviors. He found that bullying was negatively correlated with pro-social behaviors.

Gender differences are often investigated when addressing bullying and bullying experiences. It was found that boys tend to bully more frequently than girls between the sixth and eighth grades (13). Boys also tend to bully others to elevate their own perceived masculinity through the demonstration of roughness and toughness, while girls tend to bully others as a form of punishment toward individuals who do not fit societal norms, such as bullying someone for being overweight or dressing against the social norm $(13,14)$. Boys were at least one and a half times at higher risk of being a bully when compared to girls (15). Boy bullies scored higher on physical bullying than did girl bullies, while scoring equivalent to girls on both verbal and relational bullying (15). These findings again demonstrate that boys tend to express masculinity through bullying and in their bullying type (physical), while girls tend to bully their victims using verbal and relational means. While there is no single answer as to why males score higher than girls on physical aggression, for the potential relationship between bullying and moral disengagement, one may look again to societal norms for boys, such as being tough, disengaging with feelings, and hiding emotion.

\subsection{Discrimination Experiences among Korean-Americans}

It is crucial to understand psychological issues among Asian-American adolescents, as they experience higher levels of mental health issues than EuropeanAmerican adolescents (16). Many factors, such as discrimination, acculturation and generational value gaps have been documented to contribute to their mental health issues (17). Discrimination is a common factor in bully experiences among minority children and contributes to negative mental and physical health outcomes $(18,19$, 20). While one might assume that ascribing a positive stereotype to Asian-Americans would lead to a positive outcome, adolescents who experience any form of stereotyping, positive or negative, tend to have lower academic grades when compared to adolescents not stereotyped or discriminated against (21). Quin et al. (20) found that Chinese-American students experience physical bullying stemming from discrimination. Participants reported being "beaten, bullied, tripped, hit, pushed, kicked" and having objects thrown at them both inside and outside of their schools, due to their ethnicity. Chinese-American students also experienced covert discrimination when others frequently ignored them, gave them dirty looks, or avoided them. These discrimination experiences may lead to higher rates of negative mental health issues, leaving the victims with feelings of vulnerability. The accumulated discrimination experiences may develop into acceptance of deviance as they come to believe that those around them are not treating them with fairness and justice because of their ethnicity (19).

While only a few studies have investigated bullying experiences among Korean-American adolescents, none have investigated the relationship between bullying, moral disengagement and discrimination experiences among KoreanAmerican adolescents. This study examined the experiences of Korean-American adolescents who engaged in bullying in terms of moral disengagement and discrimination. Other bullying experiences among Korean-American adolescents, including the victims, have been reported in a previous study (22). In the 2011 study, Shin et al. (22) also assessed discrimination 
experiences of Korean-American high school students in relation to bullying. They found that bullies reported higher levels of discrimination when compared to nonbullies, specifically feeling unfairly treated and experiencing discomfort with peers. In addition, a significant number of the students $(31.5 \%)$ reported bullying others in this study. Those Korean-American clinicians who participated in the study interpreted this high incidence of bullying as a result of the students defending themselves against discrimination. Based on this finding, we explored bullying experiences as related to discrimination and moral disengagement, focusing on the experiences of bullies among Korean-American junior high school students.

It was hypothesized that the participants who identified themselves as bullies would show higher levels of moral disengagement when compared with nonbullies. It was hypothesized that bullies would experience higher levels of discrimination than non-bullies. It was also expected that the higher the level of moral disengagement the students demonstrated, the more likely they would be to have experienced discrimination.

We also addressed the question of gender differences by asking the following research questions:

1. Do gender differences in moral disengagement exist within the bully group?

2. Do gender differences in discrimination experiences exist within the bully group?

\section{Method}

\subsection{Participants}

Participants included 119 (42\% male and 57\% female) Korean-American students from junior high schools in New York and New Jersey. Their ages ranged from 10 to 14 years old $(M=12.50, S D=1.04)$. More than half of the students (60\%) were born in the U.S. Most of the students (80\%) lived with both parents, and others lived with only one parent or with a host family.

\subsection{Measures}

The Bully Survey (23) is a multi-part self-report questionnaire designed to measure three aspects of bullying: being bullied, observing others being bullied, and bullying others. Participants self-identified themselves as bullies, victims or observers. According to the survey, the bully experiences were defined as "punching, shoving and other acts that hurt people physically, spreading bad rumors about people, keeping certain people out of a group, teasing people in a mean way, and getting certain people to gang up on others" (Swearer \& Paulk, 1998). There were 38 participants (32\%) who identified themselves as bullies, and they are the main focus of this study. Bully tactics in this survey included "called them names," "made fun of them," and "said I will do bad things to them." Frequency information about bullying tactics used by the bullies is given in Table 1.

The survey also included one subscale section that measured moral attitudes about bullying, and this was used as a measure of moral disengagement. The questions of the survey are based on a 5-point Likert scale rating from "totally false" to "totally true." Questions included "most people who get bullied ask for it," "bullies hurt kids" and "being bullied is no big deal." Frequency information about moral disengagement is presented in Table 2. For the current study, two items that did not contribute to the internal consistency to an acceptable level were eliminated. With the remaining 12 items on the scale, the Cronbach's $\alpha$ was .75, which was comparable to previously reported reliability (Cronbach's $\alpha=.73$; Werth, Nickerson, Aloe, \& Swearer, 2015). 
Moral disengagement for the current study was measured by using the remaining 12 items on this scale.

The Perceived Ethnic and Racial Discrimination Scale (24) is a 21-item selfreport questionnaire assessing perceived discrimination by peers due to race or ethnicity. Participants rated items on a 5point Likert scale from "never" to "all the time." The questionnaire includes questions like "How often do you feel that other students in school make fun of you because of your race or ethnicity?" and "How often do other students treat you unfairly because of your race or ethnicity?" The internal consistency for the current study was .93.

The previous study (22) identified the factor structure of the scale: the factors that emerged from the analysis were unfair treatment, positive and negative stereotype, and discomfort. Positive stereotyping was measured by such questions as "other students in school expect that you will get good grades because of your race or ethnicity" and "other students in school think that you will do well in school because of your race or ethnicity." Negative stereotyping was measured by such questions as "other students in school think that you won't know the answer in class because of your race or ethnicity" and "other students in school treat you like you're not smart because of your race or ethnicity." Questions evaluating levels of discomfort included "other students in school are uncomfortable around you because of your race or ethnicity" and "other students feel threatened by you because of your race or ethnicity." Finally, questions concerning unfair treatment included "other students in school treat you with less respect because of your race or ethnicity" and "other students in school don't listen to your thoughts on things because of your race or ethnicity." We used these four factors in our data analysis.

\section{Results}

Participants were allowed to identify as bullies and/or victims based on The Bully Survey (23). Of the 119 total participants, $38(32 \%)$ identified as bullying others and $51(43 \%)$ as being bullied. Among the bullies, $70 \%$ experienced being bullied. There were 50 participants who identified as boys and 68 participants who identified as girls. One participant declined to answer and was not included in any analyses examining gender. The mean and standard deviation of the variables examined are presented in Table 3.

\subsection{Moral Disengagement}

A total score of moral disengagement was obtained by totaling the responses for each participant. As hypothesized, bullies reported higher levels of moral disengagement than non-bullies, $t(58.47)=$ $3.01, p<.01$. In addition, there was a significant difference in moral disengagement between boys and girls within the bully group, $t(36)=2.83, p<.01$ while there was no significant difference between boys and girls within the non-bully group. Boy bullies $(M=31.73, S D=8.7)$ experienced more moral disengagement than did girl bullies $(M=24.69, S D=5.67)$. An ANOVA also revealed a significant interaction revealed between bullying and gender, $F(1,109)=8.34, p<.01, \eta_{\text {partial }}^{2}=$ .07 . Boy bullies reported higher moral disengagement than boy non-bullies, girl bullies and girl non-bullies. There were also significant main effects for both bully groups, $F(1,109)=8.98, p<.01, \eta_{\text {partial }}^{2}=$ .08 , and gender, $F(1,109)=5.06, p<.05$, $\eta_{\text {partial }}^{2}=.04$, revealing that bullies show significantly higher levels of moral disengagement than non-bullies, and boys show higher levels of moral disengagement than girls. 


\subsection{Discrimination}

The Perceived Ethnic and Racial Discrimination Scale (24) was used to measure discrimination. Discrimination was computed based on the participants' total scores and scores on subdomains: discrimination by positive stereotyping, discrimination by negative stereotyping, being treated unfairly, and feeling discomfort. When the total score on discrimination was used, bullies did not report feeling discriminated against more than non-bullies, $t(112)=.54, p>.05$. Within the bully group, there was no significant difference between boys and girls. However in the non-bully group, boys experienced significantly more discrimination than girls, $t(34.25)^{1}=2.05, p$ $<.05$. There was no significant interaction between bullies and gender, $F(1,109)=$ $1.03, p>.05, \eta_{\text {partial }}^{2}=.01$. There were no main effects for bullying status and gender.

When positive stereotyping was examined, no significant difference was reported between bullies and non-bullies, $t$ $(112)=.35, p>.05$. In both bully and nonbully groups, there were no significant differences between boys and girls. There was no significant interaction between bullies and gender, $F(1,109)=.48, p>.05$, $\eta_{\text {partial }}^{2}=.004$. There were no main effects for bullying status and gender.

There was no significant difference in negative stereotyping between bullies and non-bullies, $t(112)=-.01, p>.05$. In both bully and non-bully groups, there were no significant differences between boys and girls. There was no significant interaction between bullies and gender, $F(1,109)=.28$, $p>.05, \eta_{\text {partial }}^{2}=.003$. There were no main effects for bully and non-bully groups, but boys reported experiencing more negative

\footnotetext{
${ }^{1}$ Separate variance t-tests were undertaken because there were unequal group sizes in conjunction with heterogeneity of variance.
}

stereotyping than girls, $F(1,109)=5.55, p$ $<.05, \eta_{\text {partial }}^{2}=.05$.

In terms of experiencing unfairness, no significant difference in unfairness was observed when comparing bullies to nonbullies, $t(99)=.23, p>.05$. Within bully and non-bully groups, there were no differences between boys and girls in perceiving unfairness. There was no significant interaction between bullying and gender, $F$ $(1,109)=2.09, p>.05, \eta_{\text {partial }}^{2}=.02$. There were no main effects for bullying status and gender.

There was no difference between bullies and non-bullies in terms of experiencing discomfort, $t(101)=1.1, p$ $>.05$. Within the bully group, however, boys perceived more discomfort than did girls, $t$ $(24.07)^{1}=2.32, p<.05$. Within the nonbully group, boys also perceived more discomfort than did girls, $t(32.24)^{1}=2.32, p$ $<.05$. There was no significant interaction between bullying and gender, $F(1,109)=$ $.56, p>.05, \eta_{\text {partial }}^{2}=.01$. There were no main effects for bullying status, but boys were experiencing more discomfort than girls, $F(1,109)=5.55, p<.001, \eta_{\text {partial }}^{2}=.10$.

\subsection{The relationship between moral disengagement and discrimination experiences}

It was expected that there would be a significant relationship between moral disengagement and discrimination experiences. The total score of the discrimination scale and the scores of its subdomains were correlated with the moral disengagement score. None of the discrimination scores were significantly related to that of moral disengagement except positive stereotype. Those who perceived more positive stereotype tended to be less morally disengaged, $r(117)=-.22, p$ $<.05$. Within the bully group, none of the discrimination scores were correlated with that of moral disengagement. Within the 
non-bully group, positive stereotype was negatively correlated with moral disengagement, $r(74)=-.28, p<.05$.

\section{Discussion}

The results of this study support the hypothesis that bullies experience higher levels of moral disengagement compared to those of non-bullies. These findings are consistent with those of Turner (12) and Gini et al. (9), suggesting that Korean-American adolescent bullies show moral attitudes similar to those of Caucasian-American adolescent bullies. Among the KoreanAmerican adolescents, boy bullies showed higher levels of moral disengagement than all the comparison groups. It could be that, as in the general population, Korean American boys grow up more engaged than girls in physical fights and in establishing dominant relationships, learning to value physical dominance and other types of power.

As for our hypothesis that KoreanAmerican bullies experience more discrimination than non-bullies, the findings are mixed. When the total score of the discrimination scale was examined in relation to bullying experiences, bullies did not report experiencing more discrimination than non-bullies. However, boys reported experiencing significantly more discrimination than girls within the nonbully group, while there was no difference between boys and girls within the bully group. This is not consistent with the findings of the previous study of KoreanAmerican high school students, in which bullies perceived more discrimination than did non-bullies (22). It could be that the ability to define discrimination experiences becomes more developed as the adolescents grow older. Therefore, behaviors related to discrimination could be more readily perceived as related to bullying experiences during late adolescence. However, at least some of the students in the present study, notably boys in the non-bully group, did perceive themselves as having more experiences of discrimination than girls.

When the subdomains of the discrimination scale were examined, there were no significant differences between bully and non-bully groups. However, boys reported experiencing more negative stereotypes than girls within the non-bully group. In both bully and non-bully groups, boys reported experiencing more discomfort with their peers than girls. The results based on the discrimination scale show that boys are more affected by discrimination than girls in general. Boys also seem to be less comfortable with their peers compared to girls, suggesting that they may have more difficulties in social adjustment, social inclusion, and forming social relationships with their peers.

When the relationship between discrimination and moral disengagement was examined, the results do not show that discrimination experiences have a significant impact on moral disengagement. It could be that the discrimination experiences are not directly related to moral disengagement, and it could be that they impact the victims of bullying more than the bullies. Often the behaviors that are related to discrimination are inclusive of the bullying behaviors, such as "they make a fun of me because of the way I look and of my background." These are the experiences of the victims rather than of the bullies, who may not be subjected to bullying or may not acknowledge their victimization as a form of defense or to protect their self-image. However, it is notable that the boy bullies are uncomfortable with their peers, showing more potential social adjustment issues than girls.

Again, in the previous study with high school students, bullies experienced more 
discrimination than non-bullies (22), so discrimination issues may become more salient among the older age group, and this should be studied longitudinally along with moral disengagement. This topic also should be pursued in relation to factors relevant to Korean-American culture. Many Korean-American parents are protective of their children, who are growing up as a minority group, and encourage them to learn self-defensive skills, such as Tae-Kwon-Do, which might have played a role in the relatively high percentage of these adolescents who report bullying others. In a previous study (22), the clinicians who participated in the study interpreted bullying others among Korean-American students as a form of self-defense against being bullied.

It is also conceivable that KoreanAmerican adolescents raised in conservative Koreans households, where children are expected to obey their parents and seniors, have a more hierarchical view of relationships with their peers, and may exercise aggression to demand seniority, especially within their own ethnic group. The family relationships and their social experiences within their own ethnic group should also be explored to further study the bullying experiences of these children as related to moral disengagement. To the extent that Korean cultural norms are not consistent with those of the U.S. mainstream culture, Korean-American children may be more susceptible to deviating from the accepted social norms and becoming morally disengaged.

This study supported previous findings by confirming that bullying experiences are related to moral disengagement among Korean-American adolescents. An extended sample size, inclusion of such social factors as family and in-group relationships along with discrimination experiences, and followups of these children longitudinally would further delineate how certain adolescents lose their sense of morality and become bullies and aggressors while others remain intact and resilient to negative social and school experiences. 
Medical Research Archives, Vol. 5, Issue 9, September 2017

MORAL DISENGAGEMENT AND BULLYING

Table 1. Frequency of Bullying Type

\begin{tabular}{|c|c|c|c|c|c|}
\hline & Never happened & Rarely happened & $\begin{array}{l}\text { Sometimes } \\
\text { happened }\end{array}$ & Often happened & Always happened \\
\hline Name calling & $21.10 \%$ & $34.20 \%$ & $21.20 \%$ & $21.10 \%$ & $2.60 \%$ \\
\hline Made fun of them & $10.50 \%$ & $36.80 \%$ & $23.70 \%$ & $26.30 \%$ & $2.60 \%$ \\
\hline Said bad things to them & $57.90 \%$ & $15.80 \%$ & $15.80 \%$ & $5.30 \%$ & $5.30 \%$ \\
\hline Played jokes on them & $44.70 \%$ & $18.40 \%$ & $26.30 \%$ & $2.60 \%$ & $7.90 \%$ \\
\hline Won't let them be a part of my group & $54.10 \%$ & $10.80 \%$ & $18.90 \%$ & $8.10 \%$ & $8.10 \%$ \\
\hline Break their things & $71.10 \%$ & $18.40 \%$ & $7.90 \%$ & $2.60 \%$ & N/A \\
\hline Attack them & $63.90 \%$ & $13.90 \%$ & $5.60 \%$ & $13.90 \%$ & $2.80 \%$ \\
\hline Don't talk to them & $28.90 \%$ & $23.70 \%$ & $5.30 \%$ & $21.20 \%$ & $21.20 \%$ \\
\hline Write bad things about them & $50.00 \%$ & $21.20 \%$ & $15.80 \%$ & $7.90 \%$ & $5.30 \%$ \\
\hline Said mean things behind their back & $23.10 \%$ & $17.90 \%$ & $28.20 \%$ & $12.80 \%$ & $17.90 \%$ \\
\hline Pushed them & $42.10 \%$ & $13.20 \%$ & $18.40 \%$ & $15.80 \%$ & $10.50 \%$ \\
\hline
\end{tabular}


Medical Research Archives, Vol. 5, Issue 9, September 2017

MORAL DISENGAGEMENT AND BULLYING

Table 2. Frequency of Moral Attitudes

\begin{tabular}{|l|r|r|r|r|r|}
\hline & Totally false & Sort of false & \multicolumn{2}{l|}{$\begin{array}{l}\text { Both true and } \\
\text { false }\end{array}$} & \multicolumn{2}{l|}{$\begin{array}{l}\text { Sort of } \\
\text { true }\end{array}$} & \multicolumn{2}{l|}{$\begin{array}{l}\text { Totally } \\
\text { true }\end{array}$} \\
\hline Most people who get bullied ask for it & $42.20 \%$ & $21.60 \%$ & $25.90 \%$ & $7.80 \%$ & $2.60 \%$ \\
\hline Bullying is a problem for kids & $7.70 \%$ & $6.80 \%$ & $6.80 \%$ & $21.40 \%$ & $57.40 \%$ \\
\hline Bullies are popular & $23.30 \%$ & $15.50 \%$ & $37.90 \%$ & $18.10 \%$ & $5.20 \%$ \\
\hline I don't like bullies & $8.50 \%$ & $6.00 \%$ & $12.00 \%$ & $12.80 \%$ & $60.70 \%$ \\
\hline I am afraid of bullies at school & $53.00 \%$ & $28.70 \%$ & $7.80 \%$ & $5.20 \%$ & $5.20 \%$ \\
\hline Bullying is good for wimpy kids & $69.20 \%$ & $12.80 \%$ & $12.80 \%$ & $0.90 \%$ & $4.30 \%$ \\
\hline Bullies hurt kids & $6.00 \%$ & $6.00 \%$ & $20.50 \%$ & $17.10 \%$ & $50.40 \%$ \\
\hline I would be friends with a bully & $46.20 \%$ & $21.40 \%$ & $21.40 \%$ & $6.80 \%$ & $4.30 \%$ \\
\hline I can understand why someone would & $21.40 \%$ & $15.40 \%$ & $29.90 \%$ & $22.20 \%$ & $11.10 \%$ \\
\hline bully other kids & $10.30 \%$ & $8.60 \%$ & $25.00 \%$ & $24.10 \%$ & $31.90 \%$ \\
\hline I think bullies should be punished & $38.80 \%$ & $28.40 \%$ & $25.00 \%$ & $6.00 \%$ & $1.70 \%$ \\
\hline Bullies don't mean to hurt anybody & $3.50 \%$ & $2.60 \%$ & $16.50 \%$ & $17.40 \%$ & $60.00 \%$ \\
\hline Bullies make kids feel bad & $7.80 \%$ & $7.80 \%$ & $16.40 \%$ & $20.70 \%$ & $47.40 \%$ \\
\hline I feel sorry for kids who are bullied & $57.80 \%$ & $19.00 \%$ & $15.50 \%$ & $5.20 \%$ & $2.60 \%$ \\
\hline Being bullied is no big deal & & & & \\
\hline
\end{tabular}


Medical Research Archives, Vol. 5, Issue 9, September 2017

MORAL DISENGAGEMENT AND BULLYING

Table 3. Means and Standard Deviation on the Variables examined for Each Group

\begin{tabular}{|c|c|c|c|c|c|c|c|c|c|c|c|c|c|c|c|}
\hline & \multicolumn{2}{|c|}{ Bullies $(n=38)$} & \multicolumn{3}{|c|}{ Non-Bullies $(n=76)$} & \multicolumn{5}{|c|}{ Bullies ( $n=38)$} & \multicolumn{5}{|c|}{ Non-Bullies ( $n=76$ ) } \\
\hline & \multirow[b]{2}{*}{$M$} & \multirow[b]{2}{*}{$S D$} & \multirow[b]{2}{*}{$M$} & \multirow[b]{2}{*}{$S D$} & \multirow[t]{2}{*}{$t$} & \multicolumn{2}{|c|}{ Boys $(n=22)$} & \multicolumn{2}{|c|}{ Girls ( $n=16)$} & \multirow[t]{2}{*}{$t$} & \multicolumn{2}{|c|}{ Boys $(n=27)$} & \multicolumn{2}{|c|}{ Girls ( $n=48)$} & \multirow[t]{2}{*}{$t$} \\
\hline & & & & & & $M$ & $S D$ & $M$ & $S D$ & & $M$ & $S D$ & $M$ & $S D$ & \\
\hline Moral Disengagement & 28.76 & 8.27 & 24.19 & 6.2 & $3.01^{* *}$ & 31.73 & 8.7 & 24.69 & 5.67 & $2.83^{* *}$ & 23.66 & 5.28 & 24.54 & 6.75 & -0.58 \\
\hline Discrimination (Total) & 16.19 & 14.48 & 14.72 & 13.32 & 0.54 & 16.93 & 16.97 & 15.19 & 10.56 & 0.36 & 18.91 & 17.08 & 11.69 & 8.97 & $2.05^{*}$ \\
\hline Positive Stereotype & 7.13 & 4.65 & 6.83 & 4.28 & 0.35 & 6.64 & 4.67 & 7.81 & 4.69 & 0.77 & 6.85 & 4.23 & 6.77 & 4.39 & 0.08 \\
\hline Negative Stereotype & 0.59 & 1.24 & 0.59 & 1.36 & -0.01 & 0.79 & 1.47 & 0.31 & 0.79 & 1.3 & 1.07 & 1.92 & 0.31 & 0.83 & 1.96 \\
\hline Unfairness & 6.32 & 8.23 & 5.93 & 8.94 & 0.23 & 6.23 & 9.08 & 6.44 & 7.17 & -0.77 & 8.59 & 11.88 & 3.92 & 5.35 & 1.94 \\
\hline Discomfort & 2.16 & 4.18 & 1.37 & 2.69 & 1.1 & 3.27 & 5.16 & 0.63 & 1.2 & $2.32 *$ & 2.39 & 3.62 & 0.69 & 1.65 & $2.32^{*}$ \\
\hline
\end{tabular}

${ }^{*} p<.05,{ }^{* *} p<.01,{ }^{* * *} p<.001$ 


\section{Acknowledgments}

This project was supported by funding from Catholic Korean-American Youth Research Center of the Reborn Youth Christ and sponsored by the Korean-American Behavioral Health Association. We also would like to thank Dr. Bielka for her patience and support. 


\section{References}

(1) Bradshaw, CP, Sawyer, AL, O'Brennan, LM. A social disorganization perspective on bullying-related attitudes and behaviors: the influence of school context. Am J Community Psychol. 2009; 43: 204 -220 .10.1007/s10464009-9240-1 19333749

(2) Olweus, D. Sweden. In PK Smith, Y Morita, J Junger-Tas, D Olweus, R Catalano, P Slee (Eds.), The Nature of School Bullying: A Cross-National Perspective (pp. 7-27). London: Routledge; 1999.

(3) Vaillancourt, T, McDougall, P, Hymel, S, Krygsman, A, Miller, J, Stiver, K, Davis, C. Bullying: Are researchers and children/youth talking about the same thing? Int J Behav Dev. 2008; 32(6): 486-495. doi:10.1177/0165025408095553

(4) Bandura, A. Social Foundations of Thought and Action: A Social Cognitive Theory. Englewood Cliffs, NJ: Prentice-Hall; 1986.

(5) Bandura, A. Selective activation of disengagement of moral control. J Soc Issues. 1990; 46: 27-46.

(6) Bandura, A. Selective moral disengagement in the exercise of moral agency. J Moral Education. 2002; 31(2): 101-119.

(7) Bandura, A, Grusec, JE, Menlove, FL. Vicarious extinction of avoidance behavior. J Pers Soc Psychol. 1967; 5(1): 16-23.

(8) van Noorden, TJ, Haselager, GT, Cillessen, AN, Bukowski, WM.
(2014). Dehumanization in children: The link with moral disengagement in bullying and victimization. Aggressive Behav. 2014; 40(4): 320-328. doi:10.1002/ab.21522

(9) Gini, G, Pozzoli, T, Hymel, S. Moral disengagement among children and youth: A meta-analytic review of links to aggressive behavior. Aggressive Behav. 2014; 40(1): 56-68. doi:10.1002/ab.21502

(10) Sticca, F, Perren, S. The chicken and the egg: Longitudinal associations between moral deficiencies and bullying: A parallel process latent growth model. Merrill-Palmer $Q$. 2015; $\quad$ 61(1): 85-100. doi:10.13110/merrpalmquar1982.61.1. 0085

(11) Menesini, E, Palladino, BE, Nocentini, A. Emotions of moral disengagement, class norms, and bullying in adolescence: A multilevel approach. Merrill-Palmer Q. 2015; 61(1): 124143.

doi:10.13110/merrpalmquar1982.61.1. 0124

(12) Turner, RM. Moral disengagement as a predictor of bullying and aggression: Are there gender differences? Ann Arbor: The University of Nebraska - Lincoln; 2008.

(13) Crapanzano, AM, Frick, PJ, Childs, K, Terranova, AM. Gender differences in the assessment, stability, and correlates to bullying roles in middle school children. Behav Sci Law. 2011; 29(5): 677-694. doi:10.1002/bsl.1000 
(14) Kreager, DA. Unnecessary roughness? School sports, peer networks, and male adolescent violence. Am Soc Rev. 2007; 72(5): 705-724

(15) Scheithauer, H, Hayer, T, Petermann, F, Jugert, G. Physical, verbal, and relational forms of bullying among German students: Age trends, gender differences, and correlates. Aggressive Behav. 2006: 32(3); 261-275. doi:10.1002/ab.20128

(16) Kim, E, Cain, KC. Korean American adolescent depression and parenting. $J$ Child Adolesc Psychiatric Nurs. 2008; 21(2): 105-115.

(17) Cho, S, Bae, S. Demography, psychosocial factors, and emotional problems of Korean American adolescents. Adolescence. 2005; 40(159): 522-550.

(18) Mereish, EH, Liu, MM, Helm, JE. Effects of discrimination on Chinese, Pilipino, and Vietnamese Americans' mental and physical health. Asian Am $J$ Psychol. 2012; 3(2): 91-103. doi: $10.1037 / \mathrm{a} 0025876$

(19) Lee, JP, Lee, RM., Hu, AW, Kim, OM. Ethnic identity as a moderator against discrimination for transracially and transnationally adopted Korean American adolescents. Asian Am J
Psychol, 2015; 6(2): 154-163. doi:10.1037/a0038360

(20) Qin, DB, Way, N. Rana, M. The "model minority" and their discontent: Examining peer discrimination and harassment of Chinese American immigrant youth. New Directions for Child Adolesc Dev. 2008: 27-42. doi:10.1002/cd.221

(21) Seol, KO, Yoo, HC, Lee, RM, Park, JE, Kyeong, Y. Racial and ethnic socialization as moderators of racial discrimination and school adjustment of adopted and nonadopted Korean American adolescents. J Counseling Psychol. 2016: 63(3): 294-306.

(22) Shin, JY, D'Antonio, E, Son, H, Kim, SA, Park, Y. Bullying and discrimination experiences among Korean American adolescents. $J$ Adolesc. 2011; 34: 873-883.

(23) Swearer, SM. The Bully Survey. Unpublished manuscript. Department of Educational Psychology, The University of Nebraska - Lincoln, Nebraska, United States; 2001.

(24) Way, N. The Perceived Ethnic and Racial Discrimination Scale. Unpublished Manuscript. New York University - New York, NY, United States; 1997. 